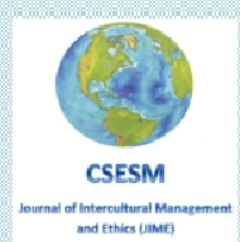

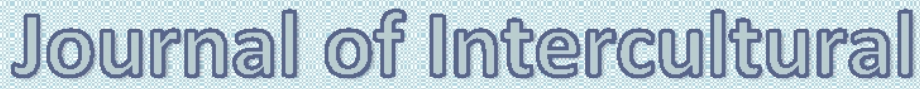

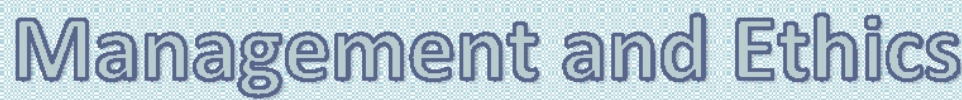

\author{
IOME
}

ISSN 2601 - 5749, ISSN-L 2601 - 5749

\section{published by zy \\ Center for Socio-Economic Studies and Multiculturalism \\ lasi, Romania \\ Waw csesmorg}




\section{TABLE OF CONTENT}

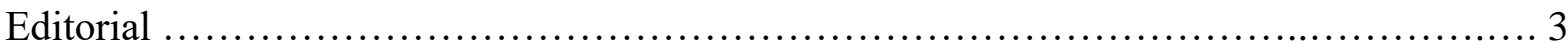

Liviu Warter

Ethics \& Consciousness in Organizations: A Conceptual Hierarchical Model

.5

Hershey H. Friedman, Kenneth A. Globerman

Ethical Challenges in Online Research.

Bianca Hanganu, Irina Smaranda Manoilescu, Beatrice Gabriela Ioan

Ethical Challenges of Digital Technologies in Covid-19 Pandemic Management. .25

Simina Petra Simion; Harald Jung

The Image of the Male and Female Doctors in the Covid-19 Pandemic. The First Pandemic with Woman Doctors in the Front Line .39 Orsolya Horber, Karoly Zilahi

Why Nations Collapse: The Rise and Fall of The United States 45

Hershey H. Friedman, Sarah Hertz

Egocentric Perceptions and Self-Serving Bias in Negotiations: Fairness, Dynamics, and Ethics 61

Oleg Komlik 


\title{
EGOCENTRIC PERCEPTIONS AND SELF-SERVING BIAS IN NEGOTIATIONS: FAIRNESS, DYNAMICS, AND ETHICS
}

\author{
Oleg Komlik \\ School of Behavioral Sciences and Psychology \\ The College of Management, Israel \\ E-mail:komliko@colman.ac.il
}

\begin{abstract}
Negotiation is one of the most common forms of social interaction and conflict resolution strategies - occurring in business, workplaces, and organizations - in which two or more parties strive to figure out an acceptable solution for their different or incompatible goals. These complex bargaining processes are always characterized by various psychological aspects. This article sheds light on two significant cognitive components impacting all facets and stages of negotiation - egocentrism and self-serving bias. Their negative effects on negotiation regarding fairness judgment, information distortion, and interactional dynamics are presented, explained, and illustrated. The paper addresses how egocentric perceptions and self-serving tendencies affect the ethical behavior of the involved parties, and it looks at these biases through intercultural lens too. The article concludes by proposing tactics and practices aimed to reduce the damaging consequences of egocentric shortcomings in negotiation and increase chances to achieve the best possible outcomes.
\end{abstract}

Keywords: egocentrism, self-serving bias, negotiation, ethics, intercultural perspective

\section{Introduction}

Everyone negotiates. Negotiation is one of the most common forms of social interaction occurring in businesses, workplaces, organizations, and in other areas, both formal and informal, of our lives. We negotiate with customers and suppliers, with supervisors and employees, with partners, colleagues, tax clerks, lawyers, shopkeepers - and this list is, in fact, endless. These bargaining processes are always characterized by psychological aspects that, to a large extent, determine how negotiations begin, in which atmosphere they are conducted, when they finish, and what the outcome will be (e.g., Klein \& Epley, 2016; Neville \& Fisk, 2019). More precisely, our expectations, perceptions, and judgment are biased in a self-serving manner, and therefore they pose a major challenge to obtain a successful resolution. This article sheds light on two significant cognitive components impacting all facets and stages of negotiation, especially in business and organizational settings - egocentrism and self-serving bias.

The second section briefly reviews an epistemological history of negotiation research. The paper's third part explains what egocentrism and self-serving bias are, and how they influence our perception and personal judgment. The fourth part demonstrates the impairing effects of these biases on negotiation (regarding fairness judgment, information distortion, interactional dynamics) and addresses how they affect the ethical behavior of the involved parties. The waves of globalization transforming business management in the recent decades require devoting the article's fifth section to discuss egocentrism in negotiation through intercultural lens. The article concludes by proposing tactics and practices aimed to reduce the negative consequences of egocentric and self-serving biases on negotiation and thus increase chances to achieve the best possible outcomes. 


\section{The short history of psychological research on negotiation}

Negotiation is one of the most common conflict resolution strategies, in which two or more parties strive to figure out a solution for their different or incompatible goals. The negotiating actors try to agree on what each party will give and what each party will take, and which concessions will be made directly or indirectly (Carnevale \& Pruitt, 1992; Rubin \& Brown, 1975; Brett, 2007). The best outcome of negotiations, especially in long-term business and social relationships, is to reach a "win-win" situation - a situation when each party feels and thinks that in the given circumstances it achieved a desirable result, even not completely. The "win-win" negotiation involves working to get the best deal possible for ourselves while also seeking to ensure that our counterpart is satisfied (Fisher, Ury, \& Patton, 1981; Susskind, 2014).

The psychological research on negotiation has gone through several upheavals over decades. In the beginning, in the 1960s and 1970s, social psychologists focused mainly on two realms. First, personal differences between negotiators: socio-demographic properties, personality traits, levels of competency, and so on. But this kind of studies, examining individual differences, eventually showed that personal characteristics have limited potential to predict the outcome of negotiations and they do not explain behavioral divergence in bargaining processes. The second early strand of research looked at structural features of negotiations: the presence of a mediator, the number of participants, varieties of incentives, deadlines, etc. These studies did reveal and indicate variables defining the context of negotiation (while most of them are objective and not controlled by negotiating parties), but they did not convincingly interpret how a negotiation structure has been created and formed. They just provided information that was consistent with intuition and their contribution to grasp the essence and dynamics of negotiation was limited (Thompson, 1998; Lewicki et al., 1993; Bazerman et al., 2000).

In the 1980s and 1990s, research on negotiations was influenced by the cognitive revolution in psychology and shifted to behavioral decision research. These studies explored how negotiators make decisions, how they perceive fairness, and to what extent they are concerned about the future of their relationship (Raiffa, 1982; Bazerman \& Neal, 1992). Their key insight was that in negotiations people rely on heuristics - simple strategies or methods that are not guaranteed to be optimal or rational but are nevertheless sufficient for reaching a goal or making a judgment, although they often lead to predictable errors and problematic outcomes (Tversky \& Kahneman, 1974). That is to say, behavioral studies on decision-making broke from and went beyond the previous psychological research framework on negotiation, emphasizing how actual decisions differ from normative and rational models. Subsequently, several new issues and aspects, that were lacking in decisionmaking research, have been raised and crystallized, and then have become pivotal in the study of negotiation: egocentrism, cognitive biases, emotions, and relationships (Bazerman et al., 2000; Bazerman, Curhan, \& Moore, 2000). The next sections thus elaborate on the subject matter of this paper: egocentric and self-serving perceptions in negotiation.

\section{What are egocentrism and self-serving bias?}

Research has consistently shown that human thinking, expectations, and ethical judgment are egocentric, and in various social and economic interactions we are biased in our own favor (Babcock et al., 1995; Thompson \& Loewenstein, 1992). According to psychological literature, egocentrism is a person's strong tendency to see a situation only from his sole point of view and an inability to discern basic concerns or evident efforts of others (Westen, 1999; Pronin \& Olivola, 2006). For instance, in Ross and Sicoly's classic study (1979) on the falseconsensus effect, married couples were asked to estimate the percentage of household chores 
they do compared to their spouse. After each of them gave a personal estimate, it turned out that the joint estimation was higher than 100 percent. The explanation for this is that each spouse focused solely on his or her own individual contribution to household chores and therefore over-appraised their own performance. Another very common egocentric shortcoming is the curse-of-knowledge effect, whereby experts fail to adequately take into consideration the level of knowledge of laypeople with whom they are communicating - just recollect your last conversation with an accountant.

Egocentrism could emerge when a person over-identifies with his or her beliefs and it is reinforced by his or her social identity (Smyth, 2002). Egocentrism is also linked to "naive realism" - people's tendency to believe that they perceive the world as an objective reality rather than realizing it is a subjective construction. Therefore, they doubt the integrity of those with whom they disagree (Wade-Benzoni, Tenbrunsel, \& Bazerman, 1996; Robinzon et al, 1995). A fascinating and yet scandalous example one can see in the Wall Street elites' behavior prior to the outbreak of 2007-8 financial and sub-prime crises. They dismissed sagacious analyzes and ignored the warnings based on extensive data about the troubling future of the U.S. credit market, attributing them to the critics' political inclinations. Moreover, captured by the illusion of control and indifferent to information contradicting their views, the Wall Street elites kept strengthening their erroneous tenets on the functioning of "free markets" (Cassidy, 2010; Madrick, 2011; Santoro \& Strauss, 2013).

According to the Freudian approach, egocentrism is understood as the ego's defense when it feels attacked and when a person's self-esteem is hurt. That is, when the ego begins to defend itself, an individual becomes egocentric (Smyth, 2002). However, it is important to emphasize that egocentrism is not egoism. Unlike an egoistic person who is self-conscious and deliberately prioritizes his own attitudes and interests over the common good and others, an egocentric person is simply certain that other people do share his perspective. Egocentrism refers to an inability to realize that another person's opinion may be dissimilar and imagine that other people would have a perception of their own regarding a case in point. The initial research on self-serving bias focused on the issue of causality attribution for negative outcomes: individuals tend to attribute success to their own abilities and efforts, but ascribe failure to external factors. Later, psychological literature defined a self-serving bias as the propensity to perceive oneself in an overly favorable manner - we tend to see ourselves better than those around us. That is, in our eyes and mind, we are fairer, more ethical, more professional, and more accountable than others. A variety of studies has showed that selfserving bias is linked to motivational, cognitive and perceptual processes that are distorted by the need to maintain and enhance self-esteem (Forsyth, 2008; Loewenstein et al., 1993; Shepperd, Malone, \& Sweeny, 2008; Klein \& Epley, 2016).

\section{Negative effects of egocentrism and self-serving bias on negotiation}

Egocentric perceptions and self-serving bias impair the ability of parties involved in negotiation to conduct it effectively and successfully, and therefore they pose a serious obstacle to achieving a solution. As the degree of negotiators' egocentrism increases, the difficulty of reaching agreement increases too (Wade-Benzoni, Tenbrunsel, \& Bazerman, 1996; Bazerman, Gillespie, \& Moore, 1999; Babcock et al., 1995).

In the context of fairness judgment, egocentric interpretation represents a dichotomous division: (my) justice versus (your) injustice, right versus wrong, good versus bad, (my) willing to compromise versus (your) refuse to do so (Epley et al., 2004). Moreover, the tendency of negotiators to compare the degree of fairness of the result to the extent of their own benefit disturbs negotiation and delays its completion. This egocentric behavior narrows the scope of the potential settlement, because each party's focus on an outcome that will only serve them reduces the range of conflict resolution proposals that could be perceived as fair 
by all parties (Babcock \& Loewenstein, 1997). The process underlying the assessment of fairness is in deciding on the preferred and beneficial outcome, and only then in justifying this decision retrospectively, using arguments of fairness - "This is the right and fair thing to do". Egocentrism makes participants in bargaining think that it is quite fair to gain more. The point is that the other side thinks the same! This aspect is well expressed, for instance, in the lack of appreciation for the opponent's concessions. The consequences of this situation are moving away from the optimal solution, prolonging the process, and damaging the relationship. In business negotiations, these implications directly inflate the parties' costs (Bazerman, 2003; Ross, 1995).

Egocentrism and self-serving bias also subvert information in negotiations. Presenting similar information to the negotiating parties (even when it is neutral information) will result in a completely different interpretation being given by them, depending on the role they play. Even when there is a sincere intention to be fair, negotiators do not understand that the interpretation they automatically attribute to information or the other party's actions is biased in their favor (Bazerman, 2003). Negotiators also tend to better remember facts and details that benefit them, and they give precedence to opinions that corroborate their arguments. On the other hand, ambiguity is undesirable in negotiations because it creates uncertainty around the perception of what the fair outcome is. Uncertainty in negotiations causes actors to interpret it in an egocentric way that is convenient for them and strengthens their standing (Diekmann et al., 1997; Thompson \& Loewenstein, 1992; Bazerman et al., 2000).

Considering dynamics in bargaining processes egocentrism and self-serving bias divert the interacting parties from the positive path as well. When negotiators' status is equal, when they hold similar roles and hierarchal positions, their egocentric perception will be weaker than in situations where they have asymmetrical ranks in their respective organizations (WadeBenzoni, Tenbrunsel, \& Bazerman, 1996). A clear example of this can be seen in recent negotiations between two Israeli financial firms: one side has sent mid-level managers to discuss a possible collaboration and the other side has been represented by the CFO. The uneven seniority of negotiators has become "the elephant in the room", the parties failed to reconcile their different perspectives and understand the other side's intentions, and this negotiation came to a standstill.

Research also shows that egocentric biases appear when people are asked to respond quickly. A rapid response does not leave enough time to correct egocentric shortcomings. In addition, a defensive response to the other party's suggestions weakens the motivational and cognitive resources needed for finding a common ground (Epley et al. 2004; Epley \& Caruso, 2004). The history of collective bargaining (negotiation between employers and employees aimed to regulate workers' compensation and conditions) in Israel demonstrates that issuing an ultimatum by an employer impelled unions to declare a strike. This illustrates that the issuance of an ultimatum not only hampers the proper course of negotiation and thus delays its successful completion, but also forces the other side to take defensive action, rather than working towards conflict resolution.

Although the discussion so far has focused on human actors, it should not be forgotten that people make up organizations, and organizations are complex systems designed to fulfill interests. So, before we move on, it is worth mentioning one specific article "The Human Mind as a Barrier to Wiser Environmental Agreement" by Bazerman, Moore, and Gillespie (1999). Looking at concrete examples from around the world, they discussed the impact of cognitive obstacles on the way to achieving arrangements regarding climate change, air and water pollution, and other environmental issues. From a deep understanding of the aspects explained above - the impact of uncertainty, egocentric judgment of fairness, the role of status difference in increasing egocentrism - the researchers presented in this 1999 article a pessimistic forecast regarding the possibility that countries and corporations will reach 
agreements on these vital global problems. They argued that biased and egocentric approaches in various disputes between countries and corporations allow them to justify ongoing harm to the environment since in the eyes of each party the proposals on the table are not fair enough. Twenty-two years later after the study was published, a pessimistic prediction by Bazerman and his colleagues turned out, unfortunately, to be true.

Ethical standards are crucial for understanding the nature and dynamics of negotiations. Along with the fact that this is a very difficult task, the distorting effects of biases appear in this context too. Negotiators fall prey to bounded ethicality, engaging in behavior that is contradictory to their values without realizing that they do so (Rees, Tenbrunsel, \& Bazerman, 2019). Egocentrism is what causes people to perceive themselves as more ethical than others (Tenbrunsel, 1998). When an unethical behavior occurs in a more overt manner, people justify it by seeing it as self-defense (Shapiro, 1991). Ethical norms in negotiation are closely and directly linked to how the "rules of the game" are defined. Understanding the nature of negotiations conveys to participants a message about the norms, boundaries, and permissible tactics, which are important because egocentrism makes parties to draw erroneous conclusions about the other party's ethics and thus intensifies a lack of trust and mutual suspicion. In this case, when one party views the other as unethical and itself as perfectly ethical, this plexus of perceptions holds back and puts off the successful completion of negotiation (Bazerman, 2003; Bazerman et al., 2000; Bazerman \& Chugh, 2006). In commercial wars, for example, violation of agreement has been often justified as a defensive act against the other side, portrayed as less ethical and evasive about its commitments.

This section described and illustrated how and when egocentrism and self-serving bias pose significant barriers to fruitful negotiations, especially regarding fairness judgment, subversion of information, bargaining dynamics, and ethical standards. The next part connects this compound discussion to the international and intercultural sphere.

\section{Egocentric and self-serving perception in an intercultural perspective.}

The current discussion would be insufficient without a chapter examining egocentrism and self-serving bias in negotiation in intercultural and international contexts. In the global world - characterized by the flow of goods, services, capital, people, and technology (Held \& McGrew, 2007; Almor, Tarba, \& Margalit, 2014) - cultural differences profoundly affect negotiators' assumptions, priorities, behaviors, and strategies (Moore \& Woodrow, 2010; Brett, 2007; Warter, 2019). Therefore, it is essential to learn how egocentrism and selfserving bias influence negotiations between representatives from different countries and regions. As explained above, biases can be defined as mental "shortcuts" used by human beings to process information as a way of dealing with a data-laden cognitive system. Ostensibly, it can be then concluded that judgment biases are universal. But many studies, however, disagree with this view and argue that these biases reflect cultural imperatives internalized by negotiators as part of the local value system. That is to say: cognitive mechanisms are not entirely universal, since they have undergone societal and cultural construction (Gelfand et al., 2002).

According to cultural psychologists, one of the most relevant dimensions to understand cultural gaps in negotiation is the issue of collectivism and individualism (Leung, 1998; Triandis, 1990). Members of individualistic cultures are characterized by loose ties between them, and they respect independence, uniqueness, and personal goals. In contrast, among members of collectivist cultures there are closer social ties, and they consider reciprocity, interdependence, and group goals (Markus \& Kitayama, 1991; Hofstede, 2001). An individualistic negotiator (e.g., from the US, the UK, or the Netherlands) focuses on preserving her rights and interests, treats negotiation as competition, strives to discuss the issue at hand and solve the conflict in the best way for her. A collectivist negotiator, on the 
contrary, (e.g., from China, Thailand, Colombia, or Romania) approaches a conflict indirectly, while trying to maintain a good relationship between the parties (Markus \& Slin, 1998; Leung, 1998).

Self-serving bias is consistent with the cultural ideals of an individualistic society, in which a person glorifies his positive qualities and advantages in order to stand out and excel over others (Heine \& Lehman, 1995). When the confrontation between the parties became more intense, American businessmen (individualists) clung to egocentric views on the perception of fairness and placed their personal goals above group goals even more (Kramer, Newton, \& Pommerenke, 1993).

Following what was said earlier regarding a dichotomous interpretation of fairness created by egocentrism (justice versus injustice), this bias is more typical in the West which has internalized the rational models. Western businesspeople negotiating in Confuciancollectivistic countries (such as China, Korea, or Japan) point out that their Asian counterparts try to avoid this simplistic and destructive division, and they aspire to create a productive fusion of incompatible positions and interests. However, it should be noted that negotiators who belong to collectivist cultures often cheat more. They do so to prevent overt confrontations and keep social harmony (Bazerman et al., 2000).

\section{Summary and potential ways to reduce egocentrism in negotiations}

To put it simply, egocentrism is an excessive self-focused attention and self-serving bias is a tendency to judge oneself in an unrealistically positive light. This article reviewed the multifaceted implications of these psychological and cognitive distortions in negotiations and bargaining processes. Although there is no consensus in the literature regarding the degree of feasibility with regard to reducing the impairing effects of egocentrism and self-serving bias (e.g., Epley \& Caroso, 2004), researchers developed - in some cases under laboratory conditions - and suggested a number of tactics to facilitate negotiators avoiding these psycho-cognitive traps:

- Negotiations should be conducted with constant reference to and consideration of facts only, while interpretating information in an even-handed and neutral manner as much as possible. In presenting a particular argument or in response to a proposal, one should think only of facts related to the subject matter in dispute and try ignoring the feelings it evokes (Babcock et al., 1995, Galinsky \& Moskowitz, 2000a).

- One de-biasing technique that has shown considerable success in reducing cognitive biases and improving decision making involves "consider the opposite" prompts negotiators should generate, list, and explain in detail reasons why their answer or proposed decisions might be wrong. This tactic is a form of "counter-attitudinal advocacy" - a role-playing exercise in which subjects are invited to articulate opinions that may not correspond with their inner convictions (Stark \& Milyavsky, 2019).

- During negotiations one should adopt as broad a perspective as possible. Biased perceptions and the stereotyping of the other side can be reduced if one breaks free from mental fixation. The ability of negotiators to observe the conflict from the other's point of view and identify the counterpart's interests and priorities is critical to the success of negotiations and the achievement of a "win-win" situation (Galinsky \& Moskowitz, 2000b; Cain, Moore, \& Loewenstein, 2005). For example, one of the cornerstones of the dispute between Israel and the Kingdom of Jordan over a particular border area has threatened to knock down peace negotiations, as each side claimed its right to this plot of land. Thinking in a broad perspective and taking into account the actual interests of the other side without sticking to the starting positions allowed the parties to find a fruitful resolution. According to the agreement, this area 
was declared under Jordanian sovereignty - fulfilling the national goals of Jordan, but Jordan leased the land to the State of Israel - fulfilling Israeli economic, agricultural, and employment interests.

- One should enter a bargaining setting with lowered expectations, and a conscious and objective assessment of his capabilities and the range of alternatives. Excessive expectations are powerful a psychological enemy in negotiations, as well as in other social interactions.

- A negotiator should understand what the failure of negotiations means to him and what costs - not just financial, but personal and social - he might bear because of this failure.

- "The most important trip you may take in life is meeting people halfway", remarked once a British statesman Henry Boyle. The bargaining actors must recognize and appreciate compromises the other party makes.

- Negotiators should endeavor maintaining good interpersonal communication - it facilitates the formation of a common outlook and shared understanding (Thompson \& Loewenstein, 1992).

It should be emphasized that the implementation of the recommendations presented above is very difficult! Even professionals whose main occupation is negotiation and who have a lot of experience with it (such as lawyers) are not immune to falling into the bias trap.

Max Bazerman, one of the most eminent researchers in the field of negotiation, summed up his advice for reducing egocentrism, in a short and simple sentence which is full of meaning: "Talking with and thinking about another side." (Bazerman 2003: 5). The following excerpt from Bazerman, Moore, and Gillespie (1999) smoothly epitomizes the gist of what has been said above:

When it comes to egocentrism, positive illusions, and over confidence, the best advice may be for negotiators to spend time thinking carefully about the position, alternatives, incentives, anchor points, and payoffs of their opponents in the dispute. The better one understands one's opponents, the better prepared one negotiates. Placing oneself in one's opponents' shoes is difficult to do, and the danger exists that sympathizing with one's opponents may weaken one's belief in the justice and glory of one's own cause. However, the alternative is to avoid the acquisition of information that, in fact, may be useful in achieving one's strategic goals in the negotiation... The best way to maximize the value of a negotiated outcome to a dispute is by gathering as much information as possible about one's own interests as well as about one's opponents' interests, to be fully informed, and to make wise decisions with that information (p. 1296).

We must be aware of the existence of the biases that make us stumble, constantly strive to avoid them, and make efforts to correct them. Moreover, we should be aware that the other side is not free from these biases either. If we do so, then our thinking and judgment will be fairer and our success in negotiating will be greater.

\section{References}

Almor, T., Tarba, S., \& Margalit, A. 2014. Maturing, Technology-based, Born Global Companies: Surviving through Mergers and Acquisitions. Management International Review, 54, 421-444.

Babcock, L., \& Loewenstein, G. (1997). Explaining Bargaining Impasse: The Role of SelfServing Biases. Journal of Economic Perspectives, 11, 109-126.

Babcock, L., Loewenstein, G., Issacharoff, S., \& Camerer, C. (1995). Biased Judgment of Fairness in Bargaining. American Economic Review, 85, 1337-1343.

Bazerman, M. (2003). The Mind of the Negotiator: When Self-Interest is Sabotage. Negotiation, 3, 3-6. 
Bazerman, M., \& Chugh, D. (2006). Bounded Awareness: Focusing Failures in Negotiation. In L. Thompson (ed.), Negotiation Theory and Research (pp. 7-26). New York: Psychology Press.

Bazerman, M., Curhan, J., \& Moore D. (2000). The Death and Rebirth of the Social Psychology of Negotiation. In M. Clark \& G. Fletcher (eds.), Blackwell Handbook of Social Psychology (pp. 196-228). Cambridge, MA: Blackwell.

Bazerman, M., Curhan J., Moore D., \& Valley K. (2000). Negotiation. Annual Review of Psychology, 51, 279-314.

Bazerman, M., Moore, D., \& Gillespie, J. (1999). The Human Mind as a Barrier to Wiser Agreements. American Behavioral Scientist, 42, 1277-1300.

Bazerman, M., \& Neal, M. (1992). Negotiating Rationally. New York: The Free Press.

Brett, J. (2007). Negotiating Globally How to Negotiate Deals, Resolve Disputes, and Make Decisions Across Cultural Boundaries. Wiley

Cain, D., Moore D., \& Loewenstein, G. (2005). The Dirt on Coming Clean: Perverse Effects of Disclosing Conflicts of Interest. The Journal of Legal Studies, 34, 1-25.

Carnevale P., \& Pruitt, D. (1992). Negotiation and Mediation. Annual Review of Psychology, 43, 531-582.

Cassidy, J. (2010). How Markets Fail: The Logic of Economic Calamities. Penguin Books.

Diekmann, K., Samuels, S., Ross, L., \& Bazerman, M. (1997). Self-Interest and Fairness in Problems of Resource Allocation. Journal of Personality and Social Psychology, 72, 10611074.

Epley, N., \& Caruso, E. (2004). Egocentric Ethics. Social Justice Research, 17(2), 171-186.

Epley, N., Keysar, B., Van Boven, L., \& Gilovich, T. (2004). Perspective Taking as Egocentric Anchoring and Adjustment. Journal of Personality and Social Psychology, 87(3), 327-339

Fisher, R., Ury, W., \& Patton, B. (1981). Getting to Yes: Negotiating Agreement Without Giving In. Penguin Books

Forsyth, D. (2008). "Self-Serving Bias". International Encyclopedia of the Social Sciences (2nd ed.). Macmillan Reference.

Galinsky, A., \& Moskowitz, G. (2000a). Counterfactuals as Behavioral Primes: Priming the Simulation Heuristic and Consideration of Alternatives. Journal of Experimental Social Psychology, 36, 384-409.

Galinsky, A., \& Moskowitz, G. (2000b). Perspective-taking: Decreasing Stereotype Expression, Stereotype Accessibility, and In-group Favorism. Journal of Personality and Social Psychology, 78, 708-724.

Gelfand, M., Higgins, M., Nishii, L., Raver, J., Alexandria, D., Murakami, F., Yamaguchi, S., \& Toyama, M. (2002). Culture and Egocentric Perceptions of Fairness in Conflict and Negotiation. Journal of Applied Psychology, 87(5), 833-845.

Heine, S., \& Lehman, D. (1995). Cultural, Self-discrepancies, and Self-satisfaction. Personality and Social Psychological Bulletin, 25, 915-925.

Held, D., \& McGrew, A. (2007). Globalization Theory: Approaches and Controversies. Cambridge: Polity Press.

Hofstede, G. (2001). Culture's Consequences: Comparing Values, Behaviors, Institutions, and Organizations Across Nations. Thousand Oaks, CA: Sage.

Klein, N., \& Epley, N. (2016). Maybe Holier, but Definitely Less Evil, than You: Bounded self-righteousness in Social Judgment. Journal of Personality and Social Psychology, 110, 660- 674.

Kramer, R., Newton, E., \& Pommerenke, P. (1993). Self-enhancement Biases and Negotiator Judgment: Effects of Self-esteem and Mood. Organizational Behavior and Human Decision Processes, 56, 110-133 
Lewicki, R., Litter, J., Saunders, D., \& Minton J. (1993). Negotiation: Readings, Exercises, and Cases. Burr Ridge, IL: Irwin.

Leung, K. (1998). Negotiation and Reward Allocations across Cultures. In P. Early \& M. Erez (eds.), New Perspectives on International Industrial / Organizational Psychology (pp. 640-675). San Francisco: Jossey-Bass Publishers.

Loewenstein, G., Issacharoff, S., Camerer, C., \& Babcock. L. (1993). Self-serving Assessments of Fairness and Pretrial Bargaining. Journal of Legal Studies, 22, 135-159.

Madrick, J. (2011). Age of Greed: The Triumph of Finance and the Decline of America, 1970 to the Present. New York: Knopf.

Markus, H., \& Kitayama, S. (1991). Culture and the Self: Implications for Cognition, Emotion, and Motivation. Psychology Review, 98, 224-253.

Markus, H., \& Lin, L. (1998). Conflictways: Cultural Diversity in the Meanings and Practices of Conflict. In D. Miller \& D. Miller (ed.), Cultural Divides (pp. 302-333). New York: Sage Publications.

Moore, W., \& Woodrow, J. (2010). Handbook of Global and Multicultural Negotiation. San Francisco, CA: Jossey-Bass.

Neville, L. \& Fisk, G. (2019). Getting to Excess: Psychological Entitlement and Negotiation Attitudes. Journal of Business and Psychology, 34, 555-574.

Pronin, E., \& Olivola, C. (2006). Egocentrism. In N. Salkind, K. DeRuyck, \& K. Rasmussen (eds.), Encyclopedia of Human Development (pp. 441-442). Thousand Oaks, CA: Sage Publications.

Raiffa, H. (1982). The Art and Science of Negotiation. Cambridge, MA: Belknep.

Rees, M., Tenbrunsel, A., \& Bazerman, M. (2019). Bounded Ethicality and Ethical Fading in Negotiations: Understanding Unintended Unethical Behavior. Academy of Management Perspectives, 33, 26-42.

Robinzon, R., Keltner, D., Ward, A., \& Ross, L. (1995). Actual versus Assumed Differences in Construal: Naïve Realism in Intergroup Perception and Conflict. Journal of Personality and Social Psychology, 68(3), 404-417.

Ross, L. (1995). Reactive Devaluation in Negotiation and Conflict Resolution. In K. Arrow et al., (eds.), Barriers to Conflict Resolution (pp. 27-42). New York: W.W. Norton \& Company. Ross, M., \& Sicoly, F. (1979). Egocentric Biases in Availability and Attribution. Journal of Personality and Social Psychology, 37, 322-336

Rubin J., \& Brown B. (1975). The Social Psychology of Bargaining and Negotiation. New York: Academic Press.

Santoro, M., \& Strauss, R. (2013). Wall Street Values: Business Ethics and the Global Financial Crisis. Cambridge University Press.

Shapiro, D. (1991). The Effects of Explanation on Negative Reaction to Deceit. Administrative Science Quarterly, 36, 614-630.

Shepperd, J., Malone, W., \& Sweeny, K. (2008). Exploring Causes of the Self-serving Bias. Social and Personality Psychology Compass, 2, 895-908.

Smyth, L. (2002). Identity-Based Conflicts: A Systemic Approach. Negotiation Journal, 18(2), 147-161.

Stark, J., \& Milyavsky, M. (2019). Towards a Better Understanding of Lawyers' Judgmental Biases in Client Representation: The Role of Need for Cognitive Closure. Washington University Journal of Law \& Policy, 59, 173-216.

Susskind, L. (2014). Good for You, Great for Me: Finding the Trading Zone and Winning at Win-Win Negotiation. Public Affairs

Tenbrunsel, A. (1998). Misrepresentation and Expectation of Misrepresentation in an Ethical Dilemma: The Role of Incentives and Temptation. Academic Management Journal, 41, 330339. 
Thompson, L. (1998). The Mind and Heart of the Negotiator. Upper Saddle River, NJ: Prentice Hall.

Thompson, L., \& Loewenstein, G. (1992). Egocentric Interpretations of Fairness and Interpersonal Conflict. Organizational Behavior and Human Decision Processes, 51, 176197.

Triandis, H. (1990). Cross-cultural Studies of Individualism and Collectivism. In J. Berman (ed.), Current Theory and Research in Motivation, Vol. 37. Nebraska Symposium on Motivation, 1989: Cross-cultural Perspectives (pp. 41-133). University of Nebraska Press.

Tversky, A., \& Kahneman, D. (1974). Judgment under Uncertainty: Heuristics and Biases. Science, 185, 1124-1131.

Wade-Benzoni, K., Tenbrunsel, A., \& Bazerman M. (1996). Egocentric Interpretations of Fairness in Asymmetric, Environmental Social Dilemmas. Organizational Behavior and Human Decision Processes, 67, 111-126.

Warter, I. (2019). Negotiation and Decision Making in Mergers and Acquisitions: Intercultural Due Diligence. New York: Nova Science Publishers.

Westen, D. (1999). Psychology: Mind, Brain, and Culture. New York: Wiley. 